\title{
Thirty years of the newborn screening program in Central Serbia: the missed cases of congenital hypothyroidism
}

\author{
Tatjana Milenkovic, Rade Vukovic, Bojana Radojicic, Katarina Mitrovic, \\ Sladjana Todorovic, Ljubica Zatezalo \\ Department of Endocrinology, Mother and Child Healthcare Institute of Serbia Dr Vukan Cupic, Belgrade, Serbia. \\ E-mail: tanjamil5e@gmail.com \\ Received: 10th March 2018, Revised: 8th May 2018, 10th June 2018, Accepted: 26th July 2018
}

SUMMARY: Milenkovic T, Vukovic R, Radojicic B, Mitrovic K, Todorovic S, Zatezalo L. Thirty years of the newborn screening program in Central Serbia: the missed cases of congenital hypothyroidism. Turk J Pediatr 2019; 61: 319324.

Newborn Screening (NS) program for congenital hypothyroidism $(\mathrm{CH})$ has completely changed the natural history of this devastating disorder for the vast majority of children with $\mathrm{CH}$. However, cases of missed $\mathrm{CH}$ do happen, and it is important to keep this possibility in mind during every day clinical practice. The objective of this study was to analyze the recognized cases of undiagnosed $\mathrm{CH}$ by the NS program in Central Serbia in order to evaluate the reasons for such omissions. Data regarding the recognized missed cases of $\mathrm{CH}$ between the years of 1983 and 2013 were collected and analyzed. During 30 years of the NS program for $\mathrm{CH}$ on the territory of Central Serbia, 1,547,122 newborns were screened, and during this period, 14 children with $\mathrm{CH}$ were missed by the NS. Five missed cases were children with athyreosis $(35.8 \%)$, 8 had ectopic thyroid gland $(57.1 \%)$ and one child had dyshormonogenesis (7.1\%). The median age at diagnosis of $\mathrm{CH}$ in these missed cases was 1.12 years (range $0.08-13.5$ years). In the group of children with missed diagnosis of $\mathrm{CH}, 71.4 \%$ were missed due to errors during sample collection, and $28.6 \%$ of patients were missed due to false negative screening results. Continuous education of neonatologists as well as nurses in neonatal units of maternity hospital are necessary to avoid errors in sample collection. It is of high importance to notice in a discharge list if a child is referred to the hospital before the sample is taken in a maternity hospital. On the other hand, the maternity hospital has to inform the screening laboratory about any child who was referred to another hospital if the blood samples for screening are not taken. Parents should be better informed that each child has to be included in the NS which is obligatory in Serbia. In addition, awareness amongst pediatricians in primary care should be raised regarding the possibility of missed cases of $\mathrm{CH}$.

Key words: newborn screening program, congenital hypothyroidism, missed cases.

Congenital hypothyroidism $(\mathrm{CH})$ is the most common preventable cause of mental retardation. If unrecognized and left untreated, $\mathrm{CH}$ can lead to severe consequences in the neurodevelopment of affected children. ${ }^{1}$ Regarding the possible prevention of such disability and easy detection by means of screening, during the last four decades, newborn screening (NS) for $\mathrm{CH}$ has become one of the mandatory aspects of health care in many countries. ${ }^{2}$
In Central Serbia, screening for $\mathrm{CH}$ was introduced in The Mother and Child Healthcare Institute of Serbia "Dr Vukan Cupic" in January 1983 by determining the TSH level in dried filter-paper blood spots, collected from 56 maternity hospitals. After establishing the diagnosis of $\mathrm{CH}$, all children were treated and followed up by pediatric endocrinologists in the same unit. Details about the methodology of the national NS program for $\mathrm{CH}$ have previously been published. ${ }^{3}$ Although the 
paramount importance of early detection of $\mathrm{CH}$ was realized after the NS program was initiated, the possibility of false negative results is well known. ${ }^{4}$ The most common causes are omissions in the screening process itself (e.g. a child small for gestational age, early admission to the neonatal intensive care unit outside the nursery, blood samples taken on the first postnatal day, twin pregnancy with same-sex twins in particular)..$^{5-7}$ The most frequent causes of omissions in the screening process are errors during sample collection and processing. ${ }^{8}$ There are other numerous reasons which may occur in the NS process: screening methodology, extreme prematurity, blood transfusion or exchange transfusion, therapy with dopamine and the usage of antithyroidal drugs during pregnancy. ${ }^{9}$

The primary objective of this research was to analyze the recognized cases of $\mathrm{CH}$ undiagnosed by the NS program in Central Serbia as well as to evaluate the reasons of such omissions.

\section{Material and Methods}

\section{Screening program}

The NS program for $\mathrm{CH}$ in Central Serbia was based on the measurements of neonatal TSH levels from its beginning. The screening process was divided into three phases: sample collection, laboratory procedures and followup phase. The collection of samples was carried out in maternity hospitals and was done by nurses in neonatal departments. Whole blood heel-prick samples were collected from all newborns between 48 and 72 hours after birth on filter paper cards and sent to the central laboratory in The Mother and Child Healthcare Institute of Serbia "Dr Vukan Cupic" for further processing. The laboratory performs an average of 55,000 screening tests per year. TSH levels were measured from the dried blood sample by radioimmunoassay (RIA) method, using the cut-off (CO) level of 30 $\mathrm{mU} / \mathrm{L}$ since the NS initiation until 12/1987, then using immunofluorometric assay (IFMA) method with CO of $15 \mathrm{mU} / \mathrm{L}$ until 12/1997 and the DELFIA method with CO of $10 \mathrm{mU} / \mathrm{L}$ until 12/2006. From 1/2007 onwards DELFIA method has been in use, but $\mathrm{CO}$ is $9 \mathrm{mU} / \mathrm{L}$. All cut-off levels have been changed according to the manufacturer's recommendations. Elevated TSH levels during NS prompted the admission to our clinic in order to confirm or exclude the diagnosis of $\mathrm{CH}$. Out of a total number of 1,547,122 newborns screened for $\mathrm{CH}$ during the study period (from January 1983 to January 2013), primary $\mathrm{CH}$ was detected in 434 newborns (260 female and 174 male). 315 patients had the permanent form of the disease, and 68 had transient $\mathrm{CH}$. In 51 children, the permanency of $\mathrm{CH}$ could not be determined (Table I). ${ }^{3}$

\section{Study design}

This was a retrospective study conducted in The Mother and Child Healthcare Institute of Serbia "Dr Vukan Cupic", approved by the Hospital's Ethics Committee and conducted in accordance with the Declaration of Helsinki. The study was based on the analysis of the discovered missed cases of $\mathrm{CH}$ from Central Serbia, which were born in the period between January 1983 and January 2013, as well as data obtained from a written questionnaire which had been sent to the heads of all pediatric

Table I. Overall Results of Newborn Screening Program for Congenital Hypothyroidism in Central Serbia for the Period 1983-2013.

\begin{tabular}{lll}
\hline & $\begin{array}{l}\text { Newborns screened for } \mathrm{CH} \\
(\mathrm{n}=434)\end{array}$ & Results of thyroid scan \\
\hline Permanent $\mathrm{CH}$ & $\mathrm{n}=315(72.6 \%)$ & $\begin{array}{l}\text { Athyreosis } 20.6 \% \\
\end{array}$ \\
& $\begin{array}{l}\text { Ectopic thyroid gland } 40.8 \% \\
\end{array}$ & $\begin{array}{l}\text { Typoplastic thyroid gland } 1.1 \% \\
\text { Thyoid gland in situ } 37.5 \%\end{array}$ \\
Transient $\mathrm{CH}$ & $\mathrm{n}=68(15.7 \%)$ & $/$ \\
Not determined & $\mathrm{n}=51(11.7 \%)$ & $/$ \\
\hline
\end{tabular}

$\mathrm{CH}$ : congenital hypothyroidism 
departments and pediatric endocrinologists on the territory of Central Serbia. In the questionnaire doctors were asked if they had a patient with $\mathrm{CH}$ who was not diagnosed by NS and if so, who made the diagnosis of $\mathrm{CH}$ and how was it established. There was also a list with the names of patients with $\mathrm{CH}$ who were missed by NS; $96 \%$ of doctors answered the questionnaire, and the remaining doctors were contacted by phone. None of them had a patient with $\mathrm{CH}$ who was not known to us and who was not treated by endocrinologist in the Mother and Child Healthcare Institute of Serbia "Dr Vukan Cupic". Central hypothyroidism was not the focus of investigation. The missed case of $\mathrm{CH}$ during screening procedure was defined as the case of $\mathrm{CH}$ that was not identified through the standard screening protocol. A missed case due to specimen collection error was defined as one for which no specimen was taken, or specimen was not sent to the laboratory. A laboratory derived missed case was defined as one that occurred within the time frame between the laboratory which received the specimen and its final report. Descriptive analyses were carried out and the results presented as absolute numbers or frequencies. The analyses were performed using SPSS version 20 (SPSS Inc, Chicago, IL).

\section{Results}

In the first twenty years of screening (from 1983 to 2002) there were ten recognized patients with $\mathrm{CH}$ that had been missed by the screening program for $\mathrm{CH}$ (Table II). The incidence of recognized missed cases of $\mathrm{CH}$ was one in 31 cases detected by the NS program.

The diagnosis of ectopia was found in five out of these ten children, four had athyreosis, and one child had dyshormonogenesis. Out of the total number of ten patients, samples from eight patients did not reach the referral laboratory, in one case, there was a mix-up of blood samples in the nursery, and the remaining case was the case of a false negative screening result. When the problem with collecting samples was observed, endocrinologist from The Mother and Child Healthcare Institute discussed the issue with pediatricians from maternity hospitals and since 2002 there have been no such errors. Patients with a false negative screening result had a screening TSH value of $32 \mathrm{mU} / \mathrm{L}$. In repeated analysis, the result was $12 \mathrm{mU} / \mathrm{L}$. Keeping in mind that TSH CO level at the time was $15 \mathrm{mU} / \mathrm{L}$, the screening result was declared negative. Nevertheless, additional evaluation was scheduled, but the child's parents did not show up and at that time, the patient was lost at follow-up. At the age of 13.5 years, the child was referred to our hospital, due to appearance of a "tumor" in the mid-lower part of the neck and neurodevelopmental delay. Laboratory analyses revealed the increased value of TSH (47.45 mU/L), and fT4 slightly below normal range $(9.93 \mathrm{pmol} / \mathrm{L})$. Scintigraphy showed the ectopic thyroid gland in the affected area of the neck. Substitution therapy with L-thyroxin was initiated subsequently. The main reason for neurodevelopmental delay was probably inherited, because both parents had the same problem of unknown origin. Hypothyroidism could be the additional factor, although it was not severe. This patient had no clinical signs of hypothyroidism.

During the period 2003-2007 there were no missed cases. From 2008 to 2013, there were other four recognized patients with missed $\mathrm{CH}$. One of them was transferred immediately after birth from nursery to the NICU of

Table II. Cases Missed by the Screening Program for CH for the Period 1983-2013.

\begin{tabular}{llll}
\hline \multirow{2}{*}{ Period } & $\begin{array}{l}\text { Sample did not reach } \\
\text { laboratory }\end{array}$ & $\begin{array}{l}\text { Mix-up of blood sample in the } \\
\text { nursery }\end{array}$ & False negative result \\
\hline 1983-2002 & $\begin{array}{l}\text { Ectopic thyroid gland (n: 4) } \\
\text { Athyreosis (n: 4) }\end{array}$ & Thyroid gland in situ (n: 1) & Ectopic thyroid gland (n: 1) \\
$2003-2007$ & - & - & - \\
$2008-2013$ & Athyreosis (n: 1$)$ & - & Ectopic thyroid gland (n: 1) \\
\hline
\end{tabular}


another hospital where the blood sample was not taken. During the second month of life, the patient was referred to our hospital for further evaluation of unconjugated hyperbilirubinemia and anemia. As part of hematological workup for jaundice, TSH and fT4 were measured. TSH was extremely high $(>1000 \mathrm{mU} / \mathrm{L})$ along with low fT4 of 0.48 $\mathrm{pmol} / \mathrm{L}$ (ref. range 10.16-20.84). Scintigraphy indicated athyreosis and substitution therapy with L-thyroxin was initiated. The patient was followed up on a regular basis. The last examination by a psychologist was done at the age of 4 . The Brunet-Lezine test revealed mild delay in neurodevelopment: QR was 70-75, mental age 34 months. In three other patients, the diagnosis of $\mathrm{CH}$ caused by the ectopic thyroid gland was established at the age of 1.5, 3.5 and 6 years, respectively. All these cases had false negative NS results, with normal NS TSH levels in all of them (2-7 mU/L). One of these children, who was admitted to hospital due to failure to thrive at the age of 15 months, had TSH level >500 mU/l and TT4 $25 \mathrm{nmol} / \mathrm{L}$ (ref. range 50-150), with no clinical signs of hypothyroidism, which was very unusual. Hormone analyses were performed as part of an investigation for short stature (length was $3 \mathrm{~cm}$ below the $3 \mathrm{rd}$ centile). Thyroid scan revealed sublingual ectopic thyroid gland. Treatment with L-Thyroxine was started immediately. At the age of 2 the BrunetLezine test was done: QR was 80-85, mental age 21 months. Six months later the family moved to another country and the patient was lost for follow up. Two other patients were referred at the ages of 3.5 and 6 years due to "tumor" in the neck. They were euthyroid with normal fT4 with mildly elevated TSH (6.39 and $7.53 \mathrm{mU} / \mathrm{L}$, respectively). Ectopic thyroid gland was confirmed on scintigraphy in both patients. L-Thyroxine therapy was initiated in both patients. During treatment, the "tumor" in the neck gradually disappeared. Neurodevelopmental assessment that was done before the treatment was normal.

During the whole study period, out of the 14 recognized missed cases of $\mathrm{CH}, 10(71 \%)$ female and 4 (29\%) male), there were 5 children with athyreosis $(35.8 \%), 8$ with ectopic thyroid gland $(57.1 \%)$ and one child with dyshormonogenesis $(7.1 \%)$. The median age at the diagnosis of $\mathrm{CH}$ in these missed cases was 1.12 years (range 0.08-13.5 years). The reasons for missed diagnosis at NS were: errors during sample collection in 10 children (71.4\%), and false negative screening result in 4 children (28.6\%) with ectopic thyroid, which had TSH values below the cutoff range.

\section{Discussion}

The results presented confirm that despite the well-organized neonatal screening procedure and properly established methodology, the missed cases of $\mathrm{CH}$ still occur, mostly due to specimen collection errors. ${ }^{10}$

Neonatal screening was proved to be an efficient measure in the prevention of disability caused by untreated $\mathrm{CH}$. Incidences of $\mathrm{CH}$ in Central Serbia detected by NS were 26.8:100,000 $(1: 3,728) .^{3}$ It has been noticed by Najafi $\mathrm{M}$ et al. ${ }^{11}$, Sullivan KM et al. ${ }^{12}$ and Azam $\mathrm{A}$ et al. $^{13}$ that, during the years of screening, the incidence of $\mathrm{CH}$ was changing as well, which was influenced by numerous factors (screening program methodology, change in TSH reference value, change in ethnical composition of the population and iodine deficiency).

Korada M, et al. ${ }^{14}$, Loeber ${ }^{15}$, and Ford and LaFranchi ${ }^{16}$ noticed that since the time when NS was introduced as a mandatory step in health care, there has been an increase of incidence of newly diagnosed patients with $\mathrm{CH}$ worldwide. Finding an increased $\mathrm{TSH}$ value at the screening is not sufficient by itself for $\mathrm{CH}$ diagnosis, but it is an initial step in the confirmation of the disease based on the analysis of TSH and T4 from the venous blood. According to results by Hyman SJ et al. ${ }^{17}$ and Grant GA et al. ${ }^{18}$, inadequate power of sole TSH level obtained from screening testing for the exclusion of the diagnosis of $\mathrm{CH}$, leads to more frequent missed cases. Some studies have shown that the incidences of $\mathrm{CH}$ also increased significantly by lowering $\mathrm{CO}$ TSH values. Corbetta et al. ${ }^{19}$ reported that the incidences of $\mathrm{CH}$ in Italy almost doubled when the TSH CO was lowered from $^{20}$ to $10 \mathrm{mU} / \mathrm{L}$, with a reduced number of missed cases. More importantly, they also reported that $45 \%$ of newly diagnosed $\mathrm{CH}$ 
newborns would be missed using the higher $\mathrm{CO}$ values. In Greece, Mengreli et al. ${ }^{20}$ and Deladoey et al. ${ }^{21}$ in Quebeck, Canada, reported a comparable increase in the incidences of $\mathrm{CH}$, and presumably lowering of the missed $\mathrm{CH}$ cases frequency, by lowering the $\mathrm{CO}$ values to $10 \mathrm{mU} / \mathrm{L}$.

During 30 years of screening in Central Serbia, the overall incidence of $\mathrm{CH}$ nearly tripled, with a significant increase in almost all etiological categories (from 1:5,943 to 1:1,872). The increase of incidences was associated with a decrease of $\mathrm{CO}$ for TSH (from the initial 30 to $9 \mathrm{mU} / \mathrm{L}) .^{3}$

Out of the total number of children covered by screening, missed $\mathrm{CH}$ was detected in 14 newborns, caused by errors during sample collection in 10 children, and false negative screening result in 4 children. Although the overall number of discovered missed cases in our study was low, the most frequent cause of missed $\mathrm{CH}$ cases were errors during the sample collection phase $(71.4 \%)$, which is consistent with the finding of Leger et al from the French screening program. When faced with this problem in our country, we had discussions with the heads of neonatal units in each maternity hospital where error sampling happened. Given that since 2002 there have been no omissions in sampling in maternity hospitals, we can be satisfied with the results. We have realized that, after 2008, there has been a problem in hospitals where children were transferred from maternity hospitals before taking a sample for screening. If there is no internal screening in those hospitals, the child could be missed from the screening process. This error can be prevented by informing the screening laboratory that the child is referred to another hospital before taking the sample. In that case, nurses who are doing the screening only, can follow the child and ask for the sample when appropriate. It is also necessary that in each hospital where neonates are treated for any reason, doctors and nurses should be aware of the necessity to do neonatal screening in each child and that the sample has to be sent to the central laboratory as soon as possible.

Parents should also be informed during pregnancy and later on in the maternity hospital that there is a neonatal screening program in the country. In such a case, parents would also be aware of it and errors of not taking samples could be minimized.

False negative results cannot be avoided. Fortunately, these cases usually have mild forms of the disease, and intellectual outcome is usually normal. On the basis of all of the above, it is clear that all clinicians, especially primary care physicians still need to think about and recognize a child with congenital hypothyroidism.

It may be concluded that, in our experience, the missed cases of $\mathrm{CH}$ still occur. Interventions that have been done reduced and practically solved the problem in the specimen collection phase in maternity hospitals. Early referral from maternity hospital and problems with collecting samples in other hospitals is still present. Internal screening in each hospital where neonates are treated should be obligatory. Well-informed parents could also help in minimizing the problem of missed cases. Also, this paper illustrates the fact that even in countries with the NS program for $\mathrm{CH}$, clinicians should be aware that even severe forms of $\mathrm{CH}$ like athyreosis can be missed, despite the NS program. It is of high importance to spread the knowledge among pediatricians and primary care physicians regarding missed $\mathrm{CH}$ as well as its recognition. Education should be provided in pediatric meetings and meetings of neonatologists, as well as through leaflets specially prepared to increase the awareness of the possibility of missed cases of $\mathrm{CH}$.

\section{REFERENCES}

1. Büyükgebiz A. Newborn screening for congenital hypothyroidism. J Clin Res Pediatr Endocrinol 2013; 5(Suppl 1): 8-12.

2. American Academy of Pediatrics AAP Section and Endocrinology and Committee on Genetics, and American Thyroid Association Committee on Public Health: Newborn screening for congenital hypothyroidism: Recommended guidelines. Pediatrics 1993; 91: 1203-1209.

3. Mitrovic K, Vukovic R, Milenkovic T, Todorovic $\mathrm{S}$, Radivojcevic J, Zdravkovic D. Changes in the incidence and etiology of congenital hypothyroidism detected during 30 years of a screening program in central Serbia. Eur J Pediatr 2016; 175: 253-259. 
4. Mengreli C, Magiakou AM, Girginoudis P, KanakaGantenbein C, Dacon-Voutetakis C. Congenital hypothyroidism $(\mathrm{CH})$; a significant number of false negative results when a cutoff point of $20 \mathrm{mU} / 1$ is applied. Horm Res 2007; 68 (Suppl 1): 218.

5. Mandel SJ, Hermos RJ, Larson CA, Prigozhin AB, Rojas DA, Mitchell ML. Atypical hypothyroidism and the very low birth weight infant. Thyroid 2000; 10: 693-695.

6. Olivieri A, Medda E, De Angelis S, et al; Study Group for Congenital Hypothyroidism. High risk of congenital hypothyroidism in multiple pregnancies. J Clin Endocrinol Metab 2007; 92: 3141-3147.

7. Sakka SD, Malamitsi-Puchner A, Loutradis D, Chrousos GP, Kanaka-Gantenbein C. Euthyroid hyperthyrotropinemia in children born after in vitro fertilization. J Clin Endocrinol Metab 2009; 94: 13381341.

8. Leger J. Screening for congenital hypothyroidism in France. Misdiagnosed cases: collaborative study of screening centres in France. Eur J Pediatr 1990; 149: 605-607.

9. Leger J, Olivieri A, Donaldson $\mathrm{M}$, et al; ESPEPES-SLEP-JSPE-APEG-APPES-ISPAE; Congenital Hypothyroidism Consensus Conference Group. European Society for Paediatric Endocrinology consensus guidelines on screening, diagnosis, and management of congenital hypothyroidism. J Clin Endocrinol Metab 2014; 99: 363-384.

10. Fisher DA. Effectiveness of newborn screening programmes for congenital hypothyroidism: Prevalence of missed cases. Ped Clin North Am 1987; 34: 881-890.

11. Najafi M, Farsi MM, Sabahi M. Primary blood TSH/ back up TSH measurements: An improved approach for neonatal thyroid screening. J Clin Lab Anal 2011; 25: 61-63.

12. Sullivan KM. Increase in congenital hypothyroidism due to inadequate iodine nutrition? Mol Genet Metab 2008; 93: 485.
13. Azam A, Cutfield W, Mouat F, et al. Missed congenital hypothyroidism in an identical twin. J Pediatr Child Health 2012; 48: 936-938.

14. Korada M, Kibirige M, Turner S, Day J, Johnstone $\mathrm{H}$, Cheetham T. The implementation of revised guidelines and the performance of a screening programme for congenital hypothyroidism. J Med Screen 2008; 15: 5-8.

15. Loeber JG. Neonatal screening in Europe; the situation in 2004. J Inherit Metab Dis 2007; 30: 430438.

16. Ford G, LaFranchi SH. Screening for congenital hypothyroidism: A worldwide view of strategies. Best Pract Res Clin Endocrinol Metab 2014; 28: 175-187.

17. Hyman SJ, Greig F, Holzman I, Patel A, Wallach E, Rapaport R. Late rise of thyroid stimulating hormone in ill newborns. J Pediatr Endocrinol Metab 2007; 20: 501-510.

18. Grant GA, Carson DJ, McCreid M, Hutchinson JM Congenital hypothyroidism missed on screening. Arch Dis Child 1986; 61: 189-197.

19. Corbetta C, Weber G, Cortinovis F, et al. A 7-year experience with low blood TSH cutoff levels for neonatal screening reveals an unsuspected frequency of congenital hypothyroidism $(\mathrm{CH})$. Clin Endocrinol 2009; 71: 739-745

20. Mengreli C, Kanaka-Gantenbein C, Girginoudis $\mathrm{P}$, et al. Screening for congenital hypothyroidism: The significance of threshold limit in false-negative results. J Clin Endocrinol Metab 2010; 95: 42834290.

21. Deladoey J, Ruel J, Giguère Y, Van Vliet G. Is the incidence of congenital hypothyroidism really increasing? A 20-year retrospective population-based study in Quebec. J Clin Endocrinol Metab 2011; 96: 2422-2429. 